\title{
Peptide receptor expression in GEP-NET
}

\author{
Jean Claude Reubi
}

Received: 11 May 2007 / Accepted: 6 June 2007 / Published online: 8 August 2007

(C) Springer-Verlag 2007

\begin{abstract}
Numerous peptide receptors have recently been reported to be expressed or overexpressed in various human cancers. For instance, somatostatin receptors are particularly frequently expressed in gastroenteropancreatic neuroendocrine tumors (GEP-NET), including both primaries and metastases. The density is often high, and the distribution is usually homogenous. While various somatostatin receptor subtypes can be expressed in these tumors, the $\mathrm{sst}_{2}$ is clearly predominant. These receptors represent the molecular basis for a number of clinical applications, including symptomatic therapy with octreotide in hormone-secreting GEP-NET, in vivo diagnostic with radiolabeled diethylene triamine pentaacetic acid octreotide (Octreoscan) to evaluate the extend of the disease, and ${ }^{90} \mathrm{Y}-$ or ${ }^{177} \mathrm{Lu}-\left[{ }^{90} \mathrm{Y}-\right.$ DOTA]-D-Phe ${ }^{1}-\mathrm{Tyr}^{3}$ octreotide radiotherapy. GEP-NET can, however, express peptide receptors other than somatostatin receptor: Insulinomas have more glucagon-like peptide 1 receptors than somatostatin receptors; gastrinomas express very high levels of secretin receptors. GEP-NET may also express cholecystokinin 2, bombesin, neuropeptide $\mathrm{Y}$, or vasoactive intestinal peptide receptors. Often, several of these peptide receptors are expressed simultaneously in GEP-NET, providing a molecular basis for in vivo multireceptor targeting of those tumors.
\end{abstract}

Keywords Peptide receptors

\footnotetext{
J. C. Reubi $(\square)$

Division of Cell Biology and Experimental Cancer Research, Institute of Pathology, University of Berne,

P.O. Box 62, Murtenstrasse 31,

CH-3010 Berne, Switzerland

e-mail: reubi@pathology.unibe.ch
}

\section{Introduction}

In the past decade, there has been increasing evidence for peptide receptor expression on various human cancers [15]. This observation has permitted to develop in vivo peptide receptor targeting of these tumors, for diagnostic and/or therapeutic purposes [12, 13, 15]. The best evidence has been provided for somatostatin receptors expressed in neuroendocrine tumors, which can currently be targeted with ${ }^{111}$ In diethylene triamine pentaacetic acid octreotide for their in vivo localization or with ${ }^{90} \mathrm{Yttrium}$ - or ${ }^{177}$ Lutetium- $\left[{ }^{90} \mathrm{Y}\right.$ DOTA]-D-Phe ${ }^{1}-$ Tyr $^{3}$ (DOTATOC) for targeted radiotherapy [12]. Somatostatin receptor scintigraphy has been shown to be the diagnostic tool of first choice for a subgroup of gut neuroendocrine tumors, as it was superior to all other conventional imaging methods [6], and radiotherapy with ${ }^{90}$ Y-DOTATOC appears extremely promising in tumors expressing somatostatin receptors, with more than $25 \%$ remissions and about $50 \%$ disease stabilization $[10,14,23$, 25]. More recently, other peptide receptors have emerged as being overexpressed in selected tumors [15] and appear to have a promising in vivo targeting potential. These are bombesin receptors of the $\mathrm{BB}_{2}$ subtype, better known as gastrin-releasing peptide (GRP) receptors, which are overexpressed in prostate and breast cancers [15] and can be visualized in vivo in these tumors [22, 24]. Furthermore, cholecystokinin (CCK) 2 receptors expressed in medullary thyroid carcinomas [15] can be selectively targeted in vivo $[1,11]$, and more recently, neurotensin receptors were visualized in exocrine pancreatic carcinomas [2].

Extensive information on in vitro peptide receptor expression including incidence, density, and subtype characteristics in tumors is required before a novel peptide receptor is chosen as target for in vivo clinical investigations in tumor patients. The aim of the present article is to 
review the in vitro evidence for the expression of several regulatory peptide receptors in cancer tissues with morphological methods, including receptor autoradiography and immunohistochemistry. It will focus on human gastroenteropancreatic neuroendocrine tumors (GEP-NET) and somatostatin receptors but will also expand to other peptide receptors such as vasoactive intestinal peptide (VIP), CCK, bombesin, neuropeptide Y (NPY), neurotensin (NT), corticotropin-releasing factor (CRF), and glucagon-like peptide (GLP-1) receptors.

\section{Somatostatin receptors in GEP-NET}

GEP-NET are generally known as a group of tumors expressing frequently somatostatin receptors. Table 1 summarizes the main features that are explained in more detail further in the text. There are several possibilities to detect somatostatin receptors morphologically in tissue sections [15]. One possibility is in situ hybridization, which, however, identifies the messenger ribonucleic acid and not the protein. Another possibility is autoradiography that identifies the receptor binding site (protein) that can be pharmacologically characterized and quantitatively assessed. It is a highly sensitive and specific method. Recently, it has been improved to identify the five somatostatin receptor subtypes by using subtype-selective analogs [18]. One drawback is, however, that in vitro autoradiography does not have a very high resolution. A method analyzing the protein with a higher resolution is receptor immunohistochemistry, which, while dependent on a high quality antibody, can precisely identify membranebound receptors in formalin-fixed tissues [16].

It is not sufficient to know whether a tumor is somatostatin receptor positive or negative; it is also necessary to assess its density, its distribution, and its somatostatin receptor subtype profile. GEP-NET can have a wide variability of somatostatin receptor density among individuals, ranging from low density, as found in lymphomas, to high density, as seen in meningiomas, medulloblastomas, or growth hormone adenomas. In the majority of the cases, GEP-NET belong preferably to the group of

Table 1 Somatostatin receptor expression in GEP-NET

\begin{tabular}{ll}
\hline Main features & Characteristics \\
\hline Receptor incidence & $\begin{array}{l}80-100 \% \text { (Most pancreatic and gut NET) } \\
50-70 \% \text { (Insulinomas) } \\
\text { predominantly high }\end{array}$ \\
Receptor density & predominantly homogeneous \\
Receptor distribution & differentiated tumor $>$ undifferentiated tumor \\
Receptor expression & $\mathrm{sst}_{2}>>\mathrm{sst}_{1}=\mathrm{Sst}_{5}>\mathrm{sst}_{3}>>\mathrm{Sst}_{4}$ \\
Receptor subtype & ${\text { usually membrane bound }\left(\mathrm{sst}_{2}\right)}^{\text {Receptor localization }}$ \\
\hline
\end{tabular}

tumors with a high density range of receptors. Both pancreatic NET (including gastrinomas, glucagomas, vipomas) and gut NET (foregut, midgut, and hind gut tumors) can express somatostatin receptors in $80-100 \%$ of the cases. Insulinomas have a lower incidence $(50-70 \%)$. In general, the somatostatin receptors are expressed homogeneously in these tumors, a characteristic that represents an advantage in view of an optimal in vivo targeting of as much tumor cells as possible during peptide receptor radiotherapy. Worth mentioning is also the differentiation-dependent expression of somatostatin receptors. Well-differentiated tumors express usually somatostatin receptors, while undifferentiated GEP-NET may not [17]. Such observations are relevant in regard to therapeutic options [9]. The existence of five sst subtypes has made the evaluation of somatostatin receptors in tumors quite complex. There is consensus, based on various methodologies, that GEP-NET can often express more than one sst subtype; moreover, sst $_{2}$ is usually the most prominent, followed by $\mathrm{sst}_{1}$ and $\mathrm{sst}_{5}$, while $\mathrm{sst}_{3}$ is less frequent and $\mathrm{sst}_{4}$ almost absent $[15,18]$. Because excellent sst $_{2}$-selective antibodies are now available, the sst $_{2}$ receptors can conveniently be assessed by immunohistochemistry on formalin-fixed tissues [7, 16, 21]; if frozen tissue is available, receptor autoradiography using subtype-selective analogs is the method of choice to identify the five sst subtypes.

In clinical practice, in vivo Octreoscan scintigraphy has become the method of choice to evaluate the somatostatin receptor status in the great majority of GEP-NET patients. It is a sensitive, specific, and noninvasive method giving receptor information for the patient's whole body. However, next to in vivo scintigraphy, the in vitro somatostatin receptor evaluation of tumors remains in specific cases an important additional current diagnostic option. It may simply be used as a complementary and confirmatory method to Octreoscan, providing information on sst subtypes, tissue localization, and on receptor homogeneity. It may replace Octreoscan if Octreoscan is not available or uneasy to interpret. The somatostatin receptor status can be established in vitro, either immunohistochemically in the formalin-fixed resected tumor using appropriate antibodies $[7,16,21]$ or, if frozen tumor tissue samples have been secured, by somatostatin receptor autoradiography [17].

\section{Other peptide receptors in GEP-NET}

Although somatostatin receptors have been found to be extremely useful targets for the diagnosis and therapy for a majority of GEP-NET, it is worth summarizing the data available for other regulatory peptide receptors in this type of tumors, as they may potentially play an equally important role. Indeed, several peptide receptors are 
Table 2 Selection of peptide receptors expressed in GEP-NET (see text for detail)

Somatostatin receptors

GLP-1 receptors

Secretin receptors

Cholecystokinin receptors

VIP receptors

Bombesin receptors

CRF receptors

NPY receptors

expressed in selected GEP-NET in much higher incidence and/or density than somatostatin receptors [18].

\section{GLP-1 receptors}

This is the case for GLP-1 receptors in insulinomas, which are expressed in virtually all cases in extremely high concentrations. We have identified several examples of insulinomas with a high density of GLP-1 receptors but no $\mathrm{sst}_{2}$ receptors [18]. Furthermore, gastrinomas express GLP1 receptors with a very high incidence but a lower density than insulinomas. One third of carcinoids have a low to moderate GLP-1 receptor density, as well as half of the four tested glucagonomas [18].

\section{CCK receptors}

CCK receptors are also widely expressed in GEP-NET. Virtually all insulinomas express $\mathrm{CCK}_{2}$ receptors, often in high amounts, but no $\mathrm{CCK}_{1}$ receptors [18]. More than half of the ileal carcinomas express $\mathrm{CCK}_{2}$ receptors, and one third expresses $\mathrm{CCK}_{1}$ receptors [18]. In several cases, both receptor subtypes are expressed concomitantly. Half of the gastrinomas express $\mathrm{CCK}_{1}$ but not $\mathrm{CCK}_{2}$ receptors.

\section{VIP receptors}

Virtually all ileal carcinomas and insulinomas and a large proportion gastrinomas and glucagonomas express $\mathrm{VPAC}_{1}$, while $\mathrm{VPAC}_{2}$ is absent [18].

\section{Bombesin receptors}

While bombesin receptors are rarely detected in insulinomas, gastrinomas express frequently the GRP receptor subtypes $\left(\mathrm{BB}_{2}\right)$, while ileal carcinoids preferentially express the neuromedin $\mathrm{B}$ receptor subtype $\left(\mathrm{BB}_{1}\right)$ [18].

\section{NPY receptors}

NPY receptors have been identified in two thirds of ileal carcinoids and one fourth of pancreatic carcinoids, in a relatively low density however (Körner and Reubi, unpublished data).

\section{Secretin receptors}

Secretin receptors are expressed in extremely high amounts in the great majority of gastrinomas cases [8]. These wildtype secretin receptors are likely to be responsible for the positive secretin provocation test in Zollinger-Ellison syndrome [5]. However, these receptors can be silenced if, exceptionally, they are expressed concomitantly with a misspliced variant with exon 3 deletion [4].

\section{CRF receptors}

Only one study has investigated CRF receptors in GEP tumors, where only endocrine pancreatic tumors were analyzed: 6 of 15 insulinomas express $\mathrm{CRF}_{2}$ receptors, while glucagomas and gastrinomas rarely express $\mathrm{CRF}_{1}$ or $\mathrm{CRF}_{2}$ receptors [20].

\section{NT receptors}

GEP-NET have not been found to express significant amounts of NT receptors [19].

\section{Multiple receptors}

It is now well documented that a large proportion of GEP-NET can express concomitantly several peptide receptors that could be used as targets simultaneously. Insulinomas often express $\mathrm{CCK}_{2}, \mathrm{GLP}-1$, $\mathrm{sst}_{2}$, and $\mathrm{VPAC}_{1}$ receptors simultaneously. Gastrinomas are characterized not only by a very high incidence and density of $\mathrm{sst}_{2}$ and secretin receptors but also a high incidence of GLP-1 receptors and a marked expression of GRP receptors [18]. The coexpression of multiple receptors in human GEP-NET may be biologically relevant [18]. Indeed, many of the involved peptides, e.g., GRP, CCK, VIP, SS, somatostatin secretin, are known to have growth stimulatory or inhibitory properties [15]. Many of these peptides will affect tumor growth, depending on the individual receptor profile of the tumor. Peptide receptor coexpression may also have clinical implications. The concomitant application of multiple radioligands may be extremely attractive to improve the efficacy of peptide targeting in tumors; it will selectively increase the accumulation of radioactivity in the tumors, an advantage not only for diagnostic but especially for radiotherapeutic purposes. Specifically, GLP-1 and $\mathrm{CCK}_{2}$ receptors may be highly efficient targets in all insulinomas, and the use of a mixture of $\mathrm{sst}_{2}$, secretin, GLP1 , and GRP radioligands could offer optimal targeting of gastrinomas. As some of the receptors are nonhomoge- 
neously expressed by tumors, such as $\mathrm{CCK}_{1}$ and $\mathrm{CCK}_{2}$ in ileal carcinoids [18], a combination of the corresponding receptor-selective radiopeptides may further improve the targeting efficacy during radiotherapy by destroying more than one receptor-expressing tumor area. Furthermore, a cocktail of different peptides may possibly reduce the risk of a loss of efficacy during peptide radiotherapy that may be due to tumor dedifferentiation with a resulting loss of some but not all peptide receptors. Finally, an advantage of using a cocktail of radioligands is the possibility to label each of them with different isotopes namely, with $\beta$ emitters of different ranges to obtain an optimal radiotherapy for large and small tumoral lesions [3]. Whenever possible, before the concomitant use of several radiopeptide ligands in vivo, it would be worth determining the individual peptide receptor affinity profile of the tumor under consideration, by in vitro receptor determination using the previously described methodology in a surgically resected biopsy sample.

Conflict of interest statement We declare that we have no conflict of interest.

\section{References}

1. Behr TM, Jenner N, Behe M, Angerstein C, Gratz S, Raue F, Becker W (1999) Radiolabeled peptides for targeting cholecystokinin-B/gastrin receptor-expressing tumors. J Nucl Med 40:10291044

2. Buchegger F, Bonvin F, Kosinski M, Schaffland AO, Prior J, Reubi JC, Blauenstein P, Tourwe D, Garcia Garayoa E, Bischof Delaloye A (2003) Radiolabeled neurotensin analog, (99m)TcNT-XI, evaluated in ductal pancreatic adenocarcinoma patients. J Nucl Med 44:1649-1654

3. de Jong M, Breeman WA, Bernard BF, Bakker WH, Visser TJ, Kooij PP, van Gameren A, Krenning EP (2001) Tumor response after [(90)Y-DOTA(0),Tyr(3)]-octreotide radionuclide therapy in a transplantable rat tumor model is dependent on tumor size. J Nucl Med 42:1841-1846

4. Ding WQ, Cheng ZJ, McElhiney J, Kuntz SM, Miller LJ (2002) Silencing of secretin receptor function by dimerization with a misspliced variant secretin receptor in ductal pancreatic adenocarcinoma. Cancer Res 62:5223-5229

5. Frucht H, Howard JM, Slaff JI, Wank SA, McCarthy DM, Maton PN, Vinayek R, Gardner JD, Jensen RT (1989) Secretin and calcium provocative tests in the Zollinger-Ellison syndrome. A prospective study. Ann Intern Med 111:713-722

6. Gibril F, Reynolds JC, Doppman JL, Chen CC, Venzon DJ, Termanini B, Weber HC, Stewart CA, Jensen RT (1996) Somatostatin receptor scintigraphy: its sensitivity compared with that of other imaging methods in detecting primary and metastatic gastrinomas. Ann Intern Med 125:26-34

7. Korner M, Eltschinger V, Waser B, Schonbrunn A, Reubi JC (2005) Value of immunohistochemistry for somatostatin receptor subtype sst2A in cancer tissues: lessons from the comparison of anti-sst2A antibodies with somatostatin receptor autoradiography. Am J Surg Pathol 29:1642-1651
8. Korner M, Hayes GM, Rehmann R, Zimmermann A, Friess H, Miller LJ, Reubi JC (2005) Secretin receptors in normal and diseased human pancreas: marked reduction of receptor binding in ductal neoplasia. Am J Pathol 167:959-968

9. Kvols LK, Reubi JC (1993) Metastatic carcinoid tumors and the malignant carcinoid syndrome. Acta Oncol 32:197-201

10. Kwekkeboom DJ, Bakker WH, Kam BL, Teunissen JJM, Kooij PP, Herder WW, Feelders RA, Eijck CHJ, Jong M, Srinivasan A, Erion JL, Krenning EP (2003) Treatment of patients with gastro-entero-pancreatic (GEP) tumours with the novel radiolabelled somatostatin analogue $\left[{ }^{177} \mathrm{Lu}-\mathrm{DOTA}{ }^{0}, \mathrm{Tyr}^{3}\right]$ octreotate. Eur J Nucl Med 30:417-422

11. Kwekkeboom DJ, Bakker WH, Kooij PP, Erion J, Srinivasan A, de Jong M, Reubi JC, Krenning EP (2000) Cholecystokinin receptor imaging using an octapeptide DTPA-CCK analogue in patients with medullary thyroid carcinoma. Eur J Nucl Med 27:1312-1317

12. Kwekkeboom DJ, Krenning EP, de Jong M (2000) Peptide receptor imaging and therapy. J Nucl Med 41:1704-1713

13. Lamberts SW, van der Lely AJ, de Herder WW, Hofland LJ (1996) Octreotide. N Engl J Med 334:246-254

14. Paganelli G, Zoboli S, Cremonesi M, Bodei L, Ferrari M, Grana C, Bartolomei M, Orsi F, De Cicco C, Macke HR, Chinol M, de Braud F (2001) Receptor-mediated radiotherapy with 90Y-DOTA-D-Phe1Tyr3-octreotide. Eur J Nucl Med 28:426-434

15. Reubi JC (2003) Peptide receptors as molecular targets for cancer diagnosis and therapy. Endocr Rev 24:389-427

16. Reubi JC, Kappeler A, Waser B, Laissue JA, Hipkin RW, Schonbrunn A (1998) Immunohistochemical localization of somatostatin receptors sst2A in human tumors. Am J Pathol 153:233-245

17. Reubi JC, Kvols LK, Waser B, Nagorney D, Heitz PU, Charboneau JW, Reading CC, Moertel C (1990) Detection of somatostatin receptors in surgical and percutaneous needle biopsy samples of carcinoids and islet cell carcinomas. Cancer Res 50:5969-5977

18. Reubi JC, Waser B (2003) Concomitant expression of several peptide receptors in neuroendocrine tumors as molecular basis for in vivo multireceptor tumor targeting. Eur J Nucl Med 30:781-793

19. Reubi JC, Waser B, Schaer JC, Laissue JA (1999) Neurotensin receptors in human neoplasms: high incidence in Ewing sarcomas. Int J Cancer 82:213-218

20. Reubi JC, Waser B, Vale W, Rivier J (2003) Expression of CRF1 and CRF2 receptors in human cancers. J Clin Endocrinol Metab 88:3312-3320

21. Schulz S, Pauli SU, Schulz S, Handel M, Dietzmann K, Firsching R, Hollt V (2000) Immunohistochemical determination of five somatostatin receptors in meningioma reveals frequent overexpression of somatostatin receptor subtype sst2A. Clin Cancer Res 6:1865-1874

22. Scopinaro F, De Vincentis G, Varvarigou AD, Laurenti C, Iori F, Remediani S, Chiarini S, Stella S (2003) ${ }^{99 \mathrm{~m}}$ Tc-bombesin detects prostate cancer and invasion of pelvic lymph nodes. Eur J Nucl Med Mol Imaging 30:1378-1382

23. Valkema R, Jamar F, Jonard P, Bakker WH, Norenberg J, Hadley J, Smith C, Kvols L, Pauwels S, Krenning EP (2000) Targeted radiotherapy with ${ }^{90}$ Y-SMT487 (Octreo Ther): a phase 1 study [Abstract]. J Nucl Med 41(Suppl):111P

24. Van de Wiele C, Dumont F, Vanden Broecke R, Oosterlinck W, Cocquyt V, Serreyn R, Peers S, Thornback J, Slegers G, Dierckx RA (2000) Technetium-99m RP527, a GRP analogue for visualisation of GRP receptor-expressing malignancies: a feasibility study. Eur J Nucl Med 27:1694-1699

25. Waldherr C, Pless M, Maecke HR, Haldemann A, Mueller-Brand J (2001) The clinical value of $\left[^{90}\right.$ Y-DOTA $^{-D}-\mathrm{Phe}^{1}-\mathrm{Tyr}^{3}$-octreotide $\left({ }^{90}\right.$ Y-DOTATOC) in the treatment of neuroendocrine tumours: a clinical phase II study. Ann Oncol 12:941-945 